including details of eight cases (two of which were recorded in our "Mirror"). This is, we believe, the first detailed account of this affection which has been given in England, and it supplements the admirable description given by Charcot in his published lectures. Two very beautiful lithograpbs, showing the naked-eye and microscopical characters of the sclerosis, illustrate Dr. Moxon's paper. Dr. Habershon draws attention to some cases illustrative of the Pathology of the Pneumogastric Nerve; and also contributes notes of some cases of Brain Disease. Venous Pulsation of the Liver, as symptomatic of tricuspid regurgitation, forms the subject of a paper by Dr. Frederick Taylor. A series of careful observations on the Blood in various inflammatory and septic diseases, together with experiments as to the "cultivation" of septicæmia, form the basis of a paper by Drs. Goodhart and Moxon. The general conclusion arrived at by the authors is that other conditions than simply a bacterogenous fluid are essential for the development of septicæmia. Dr. Goodhart also discusses the subject of Cancer. Perhaps, however, the most valuable paper included in these reports is that contributed by Dr. Galabin upon the Interpretation of Cardiographic Tracings, in which we have the application of physiological methods to the elucidation of vexed questions in cardiac patbology. Dr. Savage contributes a paper on the Insanity of Pregnancy and Childbirth; Dr. Stevenson continues his notes of Toxicological Cases; and Mr. Bader his series of drawings illustrative of Diseases of the Eye.

Our space has compelled us to give but little else than an enumeration of the contents of this volume. It will be seen that although many honoured names are conspicuous by their absence, their work has been zealously carried on by their successors, with the result that the present volume of these reports maintains the character of those that have preceded it.

We cannot close this notice, however, without drawing attention to one point. The volume is styled one of " Reports," but where are the reports? Beyond the brief statistical summary presented by Dr. Steele, there is no record or analysis of the large number of patients who passed through the wards of Guy's Hospital during the year. We trust that this conservative policy will soon be abandoned; for while the senior sister institutions and many of the younger hospitals are now affording full statistical analyses of their patients in the annual reports of their registrars, frcm Guy's, whose vast resources and ample material would render such reports of the greatest value, at present no such summaries proceed.

The Principles and Practice of Veterinary Surgery. By Wrumiam Wrictams, M R C.V.S., F.R.S.E., \&c., Principal of the New Veterinary College, ENinburgh. Second Edition. Edinburgb : Maclachlan and Stewart. London: Simpkin, Marshall, and Co.

Prof. Wrultams's work on the Principles and Practice of Veterinary Medicine and Surgery, the second edition of the first volume of which is now before us, is the most complete modern exposition of the subject which has been published in this country. Percival's elaborate work on Hippopathology, the production of a scholar and a man of varied practice, is already becoming obsolete, and the student of the veterinary art has long been in want of a well-arranged book of reference which should combine the teachings of modern science with those of the most recent experience. Mr. Williams has supplied this want in a satisfactory manner, and his book will doubtless be generally accepted as a text-book in veterinary schools.

The work is divided into two parts-the first of which deals with the external diseases of the horse and other animals; the second includes a description of the affections to which the internal organs are liable. This method of division is to some extent arbitrary, and now and then it becomes obstructive; but, so far as the student is concerned, it has certain advantages which probably more than compensate for its defects.

The second edition of the first part is an improvement on the first issue, which we noticed in favourable terms in 1872. We observe several additional illustrations, and, in particular, one of a new form of face cradle, for the treatment of fracture of the facial bones.

The chapters on Diseases of the Skin, which we have before referred to as the first attempt at classification of those disorders among the lower animals, have been extended, and now form a very important section of the work. In the description of the disease "foot-xot" among sheep, the author has introduced a critical analysis of the symptoms and morbid appearances which may be relied on as distinguishing this affection from foot-and-mouth disease in the same animal. The $t w o$ diseases are very often coniounded, and much confusion has arisen in judicial proceedings under the Contagious Diseases (Animals) Act, in consequence of the conflicting evidence of veterinary inspectors on this subject. Various authrities who have written on "foot-rot" and "foot-and-mouth disease" are quoted, and illustrations of the peculiar features of each disease are given.

We may fairly congratulate the author on the deserved success of his book; and at the same time we do not hesitate to express our conviction that the amateur in veterinary science, as well as the student and practitioner, may glean valuable information from its pages.

The Indian Alps, and how we crossed them. Being a narrative of two years' residence in the Eastern Himalaya, and two months' tour into the interior. By a Lady Pioneer, illustrated by herself. London: Longmans, Green, and Co. 1876.-This is no ordinary book, and the authoress is no ordinary lady pioneer. We have been extremely pleased with it. Written with a charming freshness and vivacity, and admirably illustrated, the style is so piquant and natural, and the smaller illustrations-pencilings by the way-are so humorous and truthful that to one who knows the Indian Alps this volume will prove most interesting reading, and create a longing in those who do not to behold the grand and varied scenery so vividly described.

The Local Government Directory, Almanack, and Guide for the Year 1876. London: Knight and Co.-This Guide is too well known to need more than a passing notice at our hands. It contains a vast amount of useful information specially required by all local authorities, most of which is very conveniently arranged and tabulated. The book is, in fact, a "requisite" in the offices of all clerks to sanitary authorities.

\section{MOVABLE AND FLOATING KIDNEYS.} To the Editor of THE LANCET.

SrR,-I am directed by the Committee appointed by the Pathological Society of London to inquire into the matter of movable and floating kidneys as verified by examination after death, to ask you to be so good as to make known that the Committee are anxious to receive details of such cases from any who have met with the like in their practice. The Committee would be greatly indebted to those members of the profession who may be able to contribute any information; and notes of the cases will be gratefully received by the undersigned, the Secretary to the Committee, at 47, Green-street, Park-lane, Lindon.

I have the bonour to be, Sir. Your most obedient servant,

Feb. 1, 1876 J. WICKHAM LEGG, M.D 